\title{
Los otros en el fútbol jujeño: una mirada desde la prensa gráfica
}

\section{The others in Jujuy's soccer: a glance from press}

\section{Ramón Burgos}

Universidad Nacional de Jujuy

cerroporito@arnet.com.ar

\section{Resumen}

El objetivo de este trabajo es realizar un análisis sobre representaciones de la otredad en el fútbol jujeño. A tal fin trabajaremos sobre diferentes superficies discursivas (entrevistas, observaciones y especialmente crónicas periodísticas), centrándonos en el club Gimnasia y Esgrima de Jujuy y su papel en la construcción de una identidad jujeña. Nos interesa indagar en las distintas maneras que "los otros" aparecen representados en este cuerpo discursivo, atendiendo especialmente al papel central de los medios de comunicación en la construcción y distribución de los imaginarios sociales.

Palabras clave: representaciones - prensa gráfica- fútbol - identidad - otros.

\section{Abstract}

The goal of this article is to analyze otherness in Jujuy's soccer game. The author works with several discourses (interviews, observations and newspaper reports), focusing on Gimnasia y Esgrima Jujuy team, and their role in building the jujeñishness identity. The author examinetes the different ways of "the others" appear to be represented in this discourse, putting careful to the main role of media in the building and distribution of social imaginaries.

Keywords: representations - press - soccer - identity - otherness.

\section{Introducción}

El objetivo de este trabajo es realizar un análisis sobre representaciones de la otredad en el fútbol jujeño ${ }^{1}$. Consideramos que en estos relatos podemos encontrar aspectos relevantes del proceso -siempre conflictivo- de construcción identitaria jujeña.

1. Jujuy se ubica en el extremo noroeste de la República Argentina. Limita al norte con Bolivia, al oeste con Chile y al sur y al este con la Provincia de Salta (ver anexo 1). 
A tal fin trabajaremos sobre diferentes superficies discursivas (entrevistas, observaciones y especialmente crónicas periodísticas) de las que hemos venido ocupándonos en nuestra investigación ${ }^{2}$, centrándonos en el club Gimnasia y Esgrima de Jujuy y su papel en la construcción de una identidad jujeña.

Nos interesa indagar en las distintas maneras que "los otros" aparecen representados en este cuerpo discursivo, atendiendo especialmente al papel central de los medios de comunicación en la construcción y distribución de los imaginarios sociales, en tanto en la actualidad se constituyen como "los principales 'proveedores' de representaciones" (Reguillo, 2005b, p $203)^{3}$.

Abordaremos las identidades sociales a partir del juego relacional de las diferencias y, en consecuencia, aceptando su carácter incompleto, abierto y, por lo tanto, inestable, contingente (Caggiano, 2005) y siempre precario (Bauman, 2005), en constante proceso de formación y transformación, implicando el proceso de identificación, y como parte de una narrativa o representación (Hall, 1995).

Así, entendemos a la identidad como "una plataforma desde la cual se interactúa con los demás, (... ) que necesita exteriorizarse, objetivarse de algún modo. Necesariamente una identidad requiere para constituirse de una alteridad, de un nosotros frente a los otros" (Reguillo Cruz, 1995, p 32).

Según Dunning (1992), este "carácter oposicional" de la identidad se da "por naturaleza" en el deporte, en tanto este elemento "es decisivo, puesto que el enfrentamiento sirve para reforzar la identificación como grupo, es decir que el sentimiento de 'nosotros' como grupo, como unidad, se refuerza ante la presencia de otro grupo percibido como 'ellos'” (p 268)

En ese marco, realizaremos un rápido recorrido que nos permita comprender cómo la relación de Gimnasia y Esgrima de Jujuy con respecto a esos “otros” permite vislumbrar parte de la conflictiva trama identitaria de la provincia, legitimando discursivamente posturas ${ }^{5}$ que nos remiten a conflictos abiertos, en torno de temáticas que desbordan lo futbolístico, como

2. Este trabajo es parte de una investigación de mayor alcance, la tesis doctoral en curso: "El papel del Club Gimnasia y Esgrima de Jujuy en la construcción de una identidad jujeña (1975-2005)”. De allí se seleccionaron distintos momentos relevantes en la historia deportiva del club para su análisis. Se hizo un relevamiento exhaustivo de los periódicos Pregón (Jujuy) y Clarín (Buenos Aires) y se realizaron entrevistas a actores relevantes de los distintos períodos analizados.

3. Baczko (1991) sostiene que la información estimula la imaginación social, y los imaginarios estimulan la información, en un proceso de circulación continua, en la que los fenómenos se contaminan permanentemente unos con otros, en "una amalgama extremadamente activa a través de la cual se ejerce el poder simbólico" (p 32). 4. Gastón Gil (2002) pone un llamado de atención sobre el "reduccionismo" que implica plantear un "universo dicotómico nosotros-ellos esquematizado" y plantea atender a la "intrincada red de alteridades que se expresan de forma variada y en situaciones distintas" que se manifiestan en los espectáculos deportivos ( $\mathrm{p} 89$ ).

5. Como sostiene Sfez (2005), postura "parece corresponder mejor a la realidad de los discursos, en el sentido de que esos discursos expresan movimientos de deseo y temor, creencias, expectativas” (p 24). 
puede serlo la de la integración de la nación por habitantes de las provincias periféricas, ya sea en su relación con la capital como en su contacto mutuo.

\section{Gimnasia, "el” club de Jujuy}

En la provincia de Jujuy, el surgimiento del fútbol como práctica deportiva tuvo el mismo origen que en el resto del país. También los británicos "lo afincaron en Jujuy, de la mano de la industrialización azucarera y el ferrocarril” (Ferreiro et al, 2000, p 170).

Archetti (2001) afirma que "los deportes de origen británico son concomitantes con la modernización, la construcción de estados nacionales yla internacionalización creciente de los intercambios económicos, sociales y culturales en el siglo XIX y comienzos del XX” (p 11).

Con todo, quienes habían imaginado una práctica de elites (Guterman, 2000), se encontraron con que esta actividad deportiva fue tomada como signo de identidad nacional y sectorial por los nuevos aficionados, convirtiéndose el fútbol en "un espejo en donde verse y ser visto al mismo tiempo" (Archetti, 2001, p 14) ${ }^{6}$.

El Club Atlético Gimnasia y Esgrima de Jujuy (en adelante GyEJ) fue fundado el 18 de marzo de 1931. Sin embargo, pasaron más de treinta años para que comenzara a ser considerado el equipo de fútbol más popular de la provincia. Su amplia supremacía en los torneos locales y sus repetidas y relativamente exitosas participaciones en los antiguos Torneos Nacionales primero, y en el Nacional B y la Primera División luego, ayudaron a cimentar esta imagen.

Paralelamente a sus actuaciones deportivas, una serie de operaciones (especialmente de la prensa gráfica local) lo presentan como el equipo más representativo de la provincia y empieza a gestarse su construcción como referente identitario.

La naturalización entre Gimnasia y Jujuy, la mayor visibilidad ${ }^{7}$ de la provincia en el ámbito nacional -a partir de "hacer trascender el nombre de Jujuy más allá del Río Las Pavas" (Pregón, 28/4/1994) - y la construcción de una identificación tendiente a agrupar al conjunto de los jujeños "tras una empresa común" (Burgos, e/p), son los pilares sobre los que se asienta el proceso de sedimentación de la idea acerca del papel de GyEJ en la construcción del imaginario jujeño (Burgos, 2002).

La historia del surgimiento de GyEJ (comola de otros muchos clubes argentinos) se cuenta en la clave épica de unos cuantos idealistas (los fundadores), pero luego el club se consolida

6. Archetti (2001) analiza cómo los deportes de equipo permiten establecer un "espacio nacional" de unificación territorial y simbólica ( p 12), señalando que, en ese sentido, el fútbol funciona "no solo como un reflejo del discurso nacionalista y patrio sino como una arena en donde ese proceso cristaliza un espacio simbólico que, con el correr de los años, será de crucial importancia en la formación de los estereotipos nacionales" (p 20).

7. Coincidimos con Reguillo (2004) en destacar la centralidad de la visibilidad, como problema clave "para el sostenimiento de identidades” y proyectos (p 260). Con relación a la visibilidad de Gimnasia y Esgrima de Jujuy, ver Burgos (2001).

8. Límite geográfico que separa, hacia el sur, a las provincias de Jujuy y Salta. 
junto al proceso de profesionalización del deporte y la expansión de los medios masivos, repercutiendo a su vez en la ciudad con una enorme capacidad referencial para constituir identidades (Gorelik, 1998, p 301).

El club constituye una sociedad definida localmente al interior de una ciudad y por contraste con lo que puede percibirse como su "exterior constitutivo": otras ciudades de la región y la nación. De modo que se produce un espacio localizado, surcado por relaciones sociales y culturales y cuya importancia en la condensación de identidades tiene una indudable faz política. Ese registro de lo político se da tanto al interior del club, por las relaciones de poder (Foucault, 1999b) tanto institucionalizadas como informales entre los agentes que lo constituyen y también en sus relaciones con otras instituciones y actores que perciben esta extraordinaria capacidad de interpelación vinculada, como dijimos, al deporte de masas en las sociedades complejas.

Como sostiene Gil (2002), la historia del fútbol argentino demuestra que "los clubes se fundaron para jugar contra alguien, contra algún enemigo al cual se le pudiera discutir el honor masculino, el prestigio del territorio propio ${ }^{9}$, una afirmación étnica y hasta una pertenencia de clase" (p 186).

Estas confrontaciones deportivas nos sitúan en la discusión identitaria. Los antropólogos Belli y Slavutsky (1994) trabajan tres tipos de acercamientos para analizar la identidad jujeña. Estos autores sostienen que

una respuesta convencional puede tomar límites de orden jurídico -se es jujeño porque se nació aquí-. Otro modo enunciativo de marcar identidad jujeña, por parte de los agentes es indicar rasgos, signos distintivos: el jujeño ama a su tierra, celebra con unción 'el éxodo jujeño ${ }^{10}$, ofrenda a la Pacha Mama, festeja el carnaval, es muy católico y venera a sus santos, etc.; o bien señala diferencias nítidas (que suelen tomar la forma de oposiciones) con la vecina provincia de Salta y con los sureños, especialmente marcado para el caso de los cordobeses y porteños ( p 121).

"En Argentina -sostiene Segato (1997)-, las identidades políticas que se derivan de una fractura inicial entre capital-puerto y provincia-interior son las que prevalecen hasta hoy como verdaderas líneas civilizatorias" ( p 9-10). En este sentido, es posible afirmar "que estos

9. Creemos que la categoría de territorio, pese a las transformaciones de la globalidad-mundo (Reguillo, 2005a), sigue siendo pertinente a los fines de los estudios sociales del deporte, sobre todo cuando se plantean dinámicas de enfrentamientos regionales, en donde priman -como sostiene Segato (2004)- "consignas nativistas poderosas [que] presionan para la formación de un sentimiento de lealtad a los emblemas de la unidad territorial” (p 13). 10. El Éxodo Jujeño aconteció el 23 de agosto de 1812. Un Bando del General Belgrano, ordenaba la retirada de todos los pobladores y la destrucción de todo aquello que no se pudiera transportar, con el objetivo de "dejar tierra arrasada" a los realistas: "llegó, pues, la época en que manifestéis vuestro heroísmo y de que vengáis a reuniros al Ejército de mi mando, si como aseguráis queréis ser libres" (29/7/1812). Este acontecimiento remite -fundamental pero no únicamente a partir de operaciones de significación propuestas por la elite local- al momento definido como fundante de la "jujeñidad" y constituye una muestra de adhesión que hace referencia a la "unidad de todo el pueblo por encima de las diferencias" (Karasik, 1994, p 45). 
alineamientos férreos y sus transformaciones a través de las generaciones impregnan y dividen la sociedad encontrando significantes hasta en niveles de la interacción que podríamos llamar de francamente microscópicos" ( $\mathrm{p} 10)$.

Esta tensión se manifiesta permanentemente en Jujuy. Como afirma Karasik (2000), "los reclamos de inclusión en el estado y la nación, de los que los jujeños parecen sentirse simbólica y socialmente excluidos, constituyen una parte fundamental de los procesos identitarios en toda esta provincia" ( $\mathrm{p} 153$ ).

En este caso, atenderemos a esas oposiciones en el marco de las competencias futbolísticas, centrándonos en la construcción de los salteños y los porteños como aquellos "otros" exteriores que son constitutivos de "lo" jujeño.

En un análisis anterior sobre las canciones de la hinchada de GyEJ (Burgos y Brunet, 2001), vimos que esos cantos están orientados principalmente a la construcción de una identidad compartida entre esos hinchas, expresada en una pertenencia común: "Gimnasia, Nosotros, Lobo, Jujuy". "Esta identificación de los hinchas como un colectivo excede los marcos estrictamente deportivos de un club de fútbol. La representación se extiende hacia la ciudad y la provincia, constituyéndose como un elemento de identificación/diferenciación provincial" ( $\mathrm{p} 36$ ).

Al mismo tiempo, y a pesar de la extensa lista de rivales deportivos, la identidad de los hinchas es configurada de manera oposicional -y casi exclusivamente- con los salteños y los porteños ${ }^{11}$.

Es interesante destacar que la diferenciación con los salteños es independiente de la confrontación directa con equipos de esa provincia ${ }^{12}$, mientras que con los porteños se da de manera ampliada, ya que esta denominación es empleada para designar a todo aquel hincha de un equipo de la ciudad o la provincia de Buenos Aires.

\section{La rivalidad con Salta/los salteños}

En el año 1834 Jujuy se autoproclamó provincia autónoma, rompiendo los lazos políticos que la ligaban con Salta. Este es uno de los tantos antecedentes a partir del cual podemos afirmar que la diferenciación y la rivalidad entre jujeños y salteños no puede explicarse solamente desde lo futbolístico. Es un aspecto más en el contexto general de enfrentamientos en lo territorial, lo étnico y lo político que se dio y se da entre estas dos provincias.

11. No profundizaremos, en este caso, la relación de los hinchas jujeños con la policía, que aparece como un tercer "otro". Para un análisis de las lógicas del comportamiento policial en las canchas, ver el excelente trabajo de Galvani y Palma (2005).

12. Si consideramos los últimos 15 años -fecha en la que Gimnasia retorna a los primeros planos del deporte nacional-, se constata que en menos de la mitad del tiempo enfrentó a equipos de Salta. En la temporada 1997/1998 se enfrentó a Gimnasia y Tiro en la Primera División, antes de que el equipo salteño descendiera de categoría. Luego del descenso de Gimnasia al Nacional B en el 2000, se enfrentó durante cinco temporadas con Juventud Antoniana, revitalizando la confrontación interprovincial. A mediados de 2005 Gimnasia ascendió nuevamente a la Primera División, mientras que el equipo salteño descendió al Torneo Argentino A. 
En el plano deportivo, y más allá de los rivales que se enfrenten en cada caso, cualquier competencia futbolística entre equipos de las provincias de Salta y Jujuy constituye -según el discurso periodístico- una recreación del clásico del norte "por la simple rivalidad que se genera en el fútbol con equipos vecinos" (Pregón, 10/10/2000), y "debido a la tradicional rivalidad entre jujeños y salteños" (Pregón, 11/3/2001). La confrontación entre estos equipos -que pone en juego "el orgullo de dos provincias" (Pregón, 19/10/2001)-, construida y alimentada históricamente, tiene un lugar destacado en los medios de comunicación regionales que hablan, justamente, desde una cultura de la rivalidad (Levatti, 1998).

Cada enfrentamiento futbolístico entre equipos jujeños y salteños presenta una "masa textual" que pone en discusión aspectos más amplios que los de una disputa futbolística

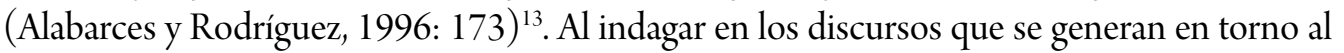
fútbol, se pueden observar fenómenos relevantes de estas sociedades que sobrepasan el ámbito deportivo y se mezclan con aspectos centrales de la vida social. Desde la justificación de la violencia policial hasta la xenofobia y la discriminación local, toda una variedad de expresiones se entremezclan en los cantos de los hinchas y en las crónicas periodísticas (Burgos, 2002). Y es en esta oposición que se actualizan rencores históricos -que "siguen los pasos de la política y la economía" (Ortíz, 2003, p 38)- pero también orgullos y rivalidades más "cotidianas".

En los discursos de la prensa gráfica local hay un tratamiento ambivalente de la violencia. Por un lado, se habla de "la fiesta del fútbol que todos queremos vivir" y se insiste en que

de una vez por todas, jujeños y salteños trasladen ese 'duelo' a las tribunas (...), pero todo dentro de (...) una verdadera fiesta deportiva, para que tanto Jujuy como Salta dejen de ser noticia en los medios nacionales por hechos ajenos al deporte, es hora que desde el pórtico norte de nuestro país se de el ejemplo de corrección (Pregón, 10/11/2002).

Sin embargo, y abonando la idea de la "exterioridad de las violencias" (Reguillo, 2003), Pregón alerta que "podrán estar presente los inadaptados de siempre que buscan en el menor detalle la oportunidad de crear el caos y los disturbios" (10/11/2002). En este sentido, las crónicas periodísticas que trabajan sobre la violencia en el fútbol pueden relacionarse con la idea de entender a estos inadaptados como monstruos (Foucault, 1999a) ${ }^{14}$.

En ese recorrido discursivo se estigmatiza al otro como el que genera los hechos de violencia. Al mismo tiempo, se produce la justificación o se hace la "vista gorda" cuando quienes sufren la violencia son los "otros". Como supo decir el presidente de GyEJ, Raúl Ulloa: "la represión policial nació debido al ataque de algunos inadaptados" (Pregón, 15/3/2001) ${ }^{15}$.

13. En este sentido también podemos observar los encuentros que en los últimos años tienen como protagonistas a Talleres de Perico (Jujuy) y Juventud Antoniana de Salta quienes han ampliando y reforzado esta confrontación provincial.

14. Un excelente análisis de la construcción del hincha en la prensa periódica está en Conde (2005).

15. Inadaptados que, por lo general, no son jujeños. Ya que el estereotipo del hincha jujeño está caracterizado "por 
En caso contrario, si la violencia es sufrida en carne propia, se la denuncia y condena. Este tipo de tratamiento de la violencia conduce a legitimar mecanismos de represión amparándose en la confrontación regional, "normalizando las violencias como parte del paisaje cotidiano" (Reguillo, 2003). Otra vez Ulloa:

En Jujuy no hay hechos de violencia, salvo el acuchillado en el partido contra River. Pero se lo merecía, porque estaba con la remera mitad de River, mitad de Talleres [de Perico]. Si no una cuchillada, por lo menos [se merecía] una bofetada deportiva (Entrevista personal, 28/11/07).

Como veremos más adelante, esta confrontación en algunos momentos entrecruza discursos con mayor grado de politicidad, tanto cuando refiere a la situación de Jujuy en el contexto nacional, como cuando cuestiona el accionar policial ${ }^{16}$.

Por último, el corpus analizado reactualiza la construcción de una mirada fuertemente xenofóbica, presente en los cantos de ambas hinchadas y en las banderas -principalmente de los equipos de Salta-. Es común que los hinchas de equipos salteños reciban a los equipos de Jujuy cantando el himno nacional argentino o al grito de "bolivianos", a lo que suele responderse con el grito de "colerosos"17. Al mismo tiempo, entre las banderas se destaca una que reza: "Jujuy, el barrio más grande de Bolivia"18.

\title{
La rivalidad con $l o / s$ porteño $/ s$
}

\begin{abstract}
"Ser una provincia limítrofe, marginada territorial, política y económicamente, nos lleva a tener una fuerza de arraigo y de identidad muy grossa. Cuando se menciona a la Argentina se menciona hasta Salta. A Jujuy se la deja de lado. Entonces, creo que todo eso hace que nosotros tengamos la identidad tan fuerte hacia lo nuestro".

Carlos "Perro" Santillán, hincha de Gimnasia y dirigente sindical
\end{abstract}

Esta rivalidad con el gran "otro", podría situarse desde la constitución misma del Estado Nacional, donde las provincias norteñas del país resultaron crecientemente marginadas "por su articulación en un modelo de desarrollo capitalista cuyo mayor dinamismo se ha ubicado en la zona pampeana y en el puerto de Buenos Aires" (Karasik, 2000, p 132-133).

ser pasivo y respetuoso de [los] espectáculos deportivos" (Pregón, 9/5/1992).

16. Ángel Causarano, directivo de Juventud Antoniana de Salta, afirmó que pese a las conversaciones previas con la Policía de Jujuy "quedó demostrado que, cuando le toca actuar, lo hace de un manera apresurada, tirando gases y balazos de goma sin sentido. No sé realmente que pensar, si esta gente por ahí actúa con saña por el hecho de tratarse de salteños, o porque no están preparados para llevar el uniforme" (El Tribuno de Salta, 11/11/2002).

17. En 1992, Salta fue el epicentro del último gran rebrote de epidemia de cólera en el país.

18. Para profundizar el análisis sobre el insulto de "boliviano" en Jujuy, ver Karasik (2005) y Caggiano (2005, 2007). 
Veremos entonces, cómo se producen recurrentemente enfrentamientos y procesos de diferenciación a través del fútbol, con los sectores "sureños" que pueden caracterizarse como hegemónicos de la identidad nacional, reactualizando permanentemente el conflicto entre el centro y la periferia.

En otro trabajo hemos analizado algunos de los momentos más destacados en la trayectoria deportiva de GyEJ, comprobando que sus campañas han resultado un campo notable para la discusión sobre las relaciones -desiguales- entre el Centro político de la Nación y una provincia periférica (Burgos, e/p, 2007).

En este caso, nos ocuparemos de lo acontecido durante el desarrollo de la fase final del campeonato Nacional de 1975, cuando GyEJ se vio involucrado en un conflicto que posicionó al fútbol en clave política.

Ante el traslado a Salta de un partido que debía jugarse en Jujuy, se levantaron voces denunciando "el centralismo" de la Asociación del Fútbol Argentino (AFA), que "como en otras épocas" no respetaba "al federalismo provincial", demostrando "que a ellos poco y nada les interesa el interior” (Pregón, 12/12/1975).

El entonces Gobernador Carlos Snopek, "en nombre del gobierno y pueblo de Jujuy", realiza una mediación oficial, ofreciendo las garantías del caso, para que el partido se juegue en la provincia. Asimismo, encomienda a varios legisladores nacionales que también intervengan en el tema, sin obtener resultados positivos.

A comienzos de 1977, motorizado por GyEJ, se presenta "la iniciativa jujeña” que propugna la realización de "un auténtico (torneo) Nacional", ya que la propuesta de disputa presentada por la AFA es considerada "atentadora contra los intereses deportivos y económicos" del fútbol del interior (Pregón, 8/1/1977). En ese contexto, se producen los preparativos del "Congreso de Jujuy", que se propone "elaborar una fórmula más adecuada para darle al fútbol del interior del país el sitial real que se merece" (Pregón, 13/1/1977), para "unir al fútbol argentino que no se cinscunscriba (sic) a la jurisdicción del obelisco, sino que se proyecte a toda la república" (Nucetelli, presidente de Talleres de Córdoba. Pregón, 15/1/1977).

Entre los despachos aprobados, que dan cuenta de la mirada crítica enunciada por los clubes, se incluyen una variada gama de reclamos entre los que se destaca la "desproporcionada inclusión de equipos de AFA con respecto a los clubes del interior, lo cual denota una evidente parcialidad de los organizadores" (Pregón, 16/1/1977). En esta dirección, se señala "la necesidad imperiosa de reestructurar al fútbol argentino", logrando una "auténtica integración del país en materia deportivo futbolística” (Ibídem).

Luego de un mes de idas y vueltas, "la postura liderada por Jujuy" (ya no por GyEJ) triunfa "de modo categórico" (Pregón, 18 y 19/2/1977). De esta manera, Pregón reafirma la "posición líder de Jujuy en el conflicto del fútbol nacional, sin más estridencia ni otra meta que las que fluyen de la propia dimensión del problema. Y la claridad de los objetivos enunciados" $(3 / 2 / 1977)$.

Pregón sostiene que el liderazgo de Gimnasia "honra y enaltece a la provincia [y] enraiza 
en la misma latencia espiritual con que en la epopeya emancipadora la tacuara criolla conectada al señero recupero de la soberanía lastimada" (sic) (Ibídem).

Es interesante observar cómo los distintos momentos relevantes de la práctica deportiva de GyEJ confluyen siempre con el relato épico de los momentos constitutivos de la identidad nacional y local, remitiendo tanto a la vinculación con la colonia como al nacimiento de la Nación, vía el papel sacrificado y valiente desempeñado por Jujuy desde su fundación y en las guerras de la independencia (Burgos y García Vargas, 2008).

De esta manera, las "gestas" deportivas jujeñas, bajo determinadas condiciones específicas, pueden adquirir "un carácter de acontecimientos sociales simbólicamente densos, de juegos profundos o de dramas sociales, en los que cada sociedad reflexiona y se imagina -y por tanto se constituye- a sí misma” (Villena Fiengo, 2000, p 145).

Un momento central en estos relatos, se produce durantela campaña del ascenso de GyEJ a la Primera División durante 1994, que se da en el marco de lo que Pregón denomina "complot" o "conspiración centralista" (Burgos, e/p).

El diario jujeño pregona a lo largo del desarrollo del campeonato una conspiración centralista en contra del equipo de GyEJ: al afirmar -en un esbozo de crítica que luego no profundizará-que

hay muchos, más precisamente de la Capital Federal o del Gran Buenos Aires, que parecen no soportar a este equipo del interior, de la provincia de Jujuy, que les está arruinando la vida, pone en peligro sus futuros negocios económicos y hasta les está provocando malestares estomacales (Pregón, 25/4/1994).

La resolución de este conflicto es vivida como una gran victoria del Interior frente al centralismo porteño: "este será el triunfo de Jujuy, de un Jujuy sufrido, postergado en muchas cosas, 'utilizado' en otras, será una revancha que llegará de la mano del fútbol” (Pregón, 9/6/1994). Un triunfo contra aquellos que querían "paladear la caída de los jujeños" y que "no podían entender, que una entidad del Norte del país, que solamente era noticia por el cólera y en estos últimos tiempos por el caso de tránsito de drogas, pudiera postergar a los de Buenos Aires" (Ibídem) ${ }^{19}$.

En este primer eje, el conflicto centro-periferia se centra en la diferenciación mediante la oposición al poder central.

Este proceso toma otro cariz a partir de un hecho que se produce en Buenos Aires en la

19. Nuevamente aparece el relato épico. La campaña futbolística de GyEJ se define como una "patriada (...) contra los grandes intereses capitalinos" y se utiliza el paralelo de la movilización de los hinchas hacia Córdoba como un nuevo momento fundante en la historia -no sólo deportiva- de Jujuy. "Dentro de pocas horas comenzará una nueva 'movilización'. ( ... Se iniciará (...) un nuevo éxodo jujeño” (Pregón, 26/4/1994). El tópico se repite en ocasión del último ascenso: "San Salvador de Jujuy lució desierta ayer en horas de la tarde, como si un nuevo éxodo hubiese dejado la ciudad vacía” (Pregón, 26/6/2005). 
anteúltima fecha. Allí, los cinco mil hinchas que viajaron mil seiscientos kilómetros desde Jujuy fueron maltratados por la Policía Federal, encargada del operativo de seguridad.

A partir de ese momento, la construcción del discurso -que venía centrado en el eje diferenciador- se vuelca hacia la demanda de inclusión, generando un doble juego de diferenciación-inclusión. Es de esta forma que el reclamo se puede sintetizar en lo expresado por el presidente de la institución jujeña, quien manifestó que "nos trataron como si no fuéramos de este país". "Una vez más parece ser, esta vez a través del fútbol, que JUJUY es una provincia que no pertenece a la Argentina, salvo que la necesiten para otros fines, como ha ocurrido en algunas oportunidades" (Pregón, 20/6/1994).

Con relación a este suceso, el entonces diputado nacional por el Movimiento de Renovación Cívica, Pedro Figueroa, dirigió una nota al Ministerio del Interior "en nombre del pueblo de Jujuy, injusta y torpemente ofendido”, en la que retoma las palabras de Snopek casi veinte años después, y destaca que "los argentinos somos y seremos todos iguales para bien y para mal, le guste al puerto o no”.

Mientras tanto, en la Legislatura provincial, diputados del Movimiento Popular Jujeño elevaron un articulado condenando la metodología implementada por los efectivos de la Policía Federal Argentina, quienes "violaran expresas disposiciones constitucionales, avasallando los derechos, privilegios e inmunidades de ciudadanos jujeños, al maltratar injustificadamente a simpatizantes y seguidores de aquel equipo de fútbol” (Pregón, 21/6/1994).

De esta manera, el reclamo de inclusión (un reclamo que excede claramente los marcos deportivos) se da en el terreno político institucional. En el reclamo de ser tratados "como argentinos", subyace una diferenciación con el que es extranjero ${ }^{20}$, trayendo a colación una voluntad de apartarse de los habitantes de otras nacionalidades (especialmente, y dada la situación de frontera de la provincia, de alejarse de lo boliviano), como si lo 'nacional' habilitara directamente a la ciudadanía.

Puede afirmarse entonces que

el reclamo de ser argentino no es, naturalmente unívoco, y constituye un espacio políticoideológico donde se enfrentan fuertes contradicciones. Bajo ciertas condiciones podrán priorizarse los aspectos más reaccionarios del discurso de la nacionalidad (la adhesión a la cultura oficial, la hostilidad contra los bolivianos), pero bajo otras condiciones puede representar la demanda de participación y democratización real de la sociedad, al amparo (de) la común membresía al sistema político (Karasik, 1994, p 69).

20. "La situación de frontera política y social de la provincia y la historia de sus relaciones sociales, ha promovido en Jujuy lo que podría llamarse estrategias de distanciamiento simbólico en relación a lo qolla y lo boliviano. Estas prácticas sobre la memoria y sobre la identidad, aparecen exacerbadas y resignificadas en esta situación puntual de frontera, como parte de los reclamos de inclusión en el estado-nación por parte de los [jujeños]" (Karasik, 2000, p 179). 
Creemos que en estos reclamos de inclusión y pertenencia podemos encontrar ambos aspectos.

En primera instancia se denuncia, a través del fútbol, un orden de cosas injusto que se refleja a través de la competencia deportiva, excediéndola, y marca referencias más amplias, vinculadas a una relación asimétrica con la nación. Sin embargo, a partir de la represión policial sufrida por los hinchas gimnasistas en Buenos Aires, el eje del reclamo cambia, introduciendo -veladamente- referencias a los extranjeros, haciéndose eco -como señala Karasik- del aspecto más reaccionario del discurso de la nacionalidad.

Así, la campaña futbolística de Gimnasia y Esgrima de Jujuy opera como un fuerte referente identitario a partir del cual se manifiestan reclamos de inclusión que, además de deportiva, son reclamos territoriales, políticos y simbólicos ${ }^{21}$.

\section{A modo de cierre}

La discusión acerca de lo local y lo nacional (y su inclusión en lo que se percibe como tal) aparecen en Jujuy con características particulares, remitiendo permanentemente a cuestiones irresueltas al interior de lo que se concibe como la sociedad jujeña y a sus relaciones con la percepción de sus exteriores constitutivos. En este sentido, el fútbol en Jujuy especifica cuestiones aún no abordadas, evidenciando no solamente la construcción de la nación, sino también la lectura "interior" del cuerpo nacional, y de sus dificultades para la integración de regiones no metropolitanas ni rioplatenses.

El caso del fútbol jujeño "expresa, condensa, visibiliza y acentúa las diferencias y los antagonismos regionales" (Ramírez Gallegos, 2003, p 102) cuando se hace referencia a esos "otros".

En este contexto, como sostiene Reguillo (2005b), "la pregunta por el otro cobra renovada vigencia" ( $\mathrm{p}$ 64), en tanto "en el fondo, la disputa es una versión que mantiene, en lo sustantivo, la permanencia de la -supuesta- homogeneidad comunitaria frente a la amenaza del hereje, el disidente, el loco, el extranjero, el anómalo, el otro diferente" (Ibídem).

"En un ambiente totalitario" afirma Segato (2004), "el valor más martillado es el nosotros. El concepto de nosotros se vuelve defensivo, atrincherado, patriótico, y quien lo infringe es acusado de traición" ( $\mathrm{p} 14$ ).

Revisar las narrativas, los discursos que van construyendo esos otros constitutivos y al mismo tiempo, ese nosotros atrincherado, nos permite indagar en las complejas dinámicas de construcción de la/s identidad/es jujeña/s.

21. Aunque de manera atenuada, la disputa centro-periferia también se hizo presente en los relatos del último ascenso de Gimnasia en 2005 (Burgos, e/p). 


\section{Referencias bibliográficas}

Alabarces, P. y Rodríguez, M. G. (1996). Cuestión de pelotas. Buenos Aires: Atuel.

Archetti, E. (2001). El potrero, la pista y el ring. Las patrias del deporte argentino. Buenos Aires: F.C.E.

Baczko, B. (1991). Los imaginarios sociales. Memorias y esperanzas colectivas. Buenos Aires: Nueva Visión.

Bauman, Z. (2005). Identidad. Buenos Aires: Losada.

Belli, E. y Slavutsky, R. (1994) "Flores, reinas y carrozas. Reflexiones sobre la identidad en San Salvador de Jujuy”. En: Cultura e identidad en el Noroeste argentino. Buenos Aires: CEAL.

Burgos, R. y Brunet, M. (2001). "Los cantos en el fútbol. El caso de Gimnasia y Esgrima de Jujuy”. En: Estudios sobre deporte. Buenos Aires: Libros del Rojas/Universidad de Buenos Aires.

Burgos, R. y García Vargas, A. (2008). “ 'El irrenunciable desafío de trabajar por Jujuy y su gente.. Actores, cultura e identidad en el suplemento 50 aniversario de Pregón”. Oficios Terrestres № 21.

Burgos, R. (dic. 2002). "El clásico del norte: un espacio para la disputa ¿deportiva?”. Revista Lecturas: Educación Física y Deportes No 55. Obtenido el 19 de enero de 2003 en http://www.efdeportes. com/efd55/norte.htm.

- (2001). Gimnasia y Esgrima de Jujuy como referente identitario. Visibilidad, fútbol y política. Tesis de Licenciatura en Comunicación Social. Universidad Nacional de Jujuy.

_ (2007). "Fútbol e identidad nacional. El caso del Torneo Nacional de 1977". En: Sobresentidos. Estudios sobre Comunicación, Cultura y Sociedad. Universidad Nacional de Jujuy.

_ (e/p). “ 'Viva Jujuy'. Gimnasia y Esgrima y la construcción de lo jujeño en la prensa gráfica”. Cuadernos del Sur No 35-36.

Caggiano, S. (2007). "Racismos y nación ante la inmigración. La percepción del "otro”, la cultura y los derechos en la producción de fronteras". Oficios Terrestres № 19.

- (2005). Lo que no entra en el crisol. Inmigración boliviana, comunicación intercultural y procesos identitarios. Buenos Aires: Prometeo.

Conde, M. (2005). "La invención del hincha en la prensa periódica”. En: Hinchadas. Buenos Aires: Prometeo.

Dunning, E. (1992). "La dinámica del deporte moderno: notas sobre la búsqueda de triunfos y la importancia social del deporte”. En: Deporte y ocio en el proceso de la civilización. México: F.C.E.

Ferreiro, J. P.; Brailovsky, S.; Blanco, E. (2000). "Identidad y poder en el fútbol: algunas reflexiones a partir de la experiencia jujeña”. En: Peligro de gol. Estudios sobre deporte y sociedad en América Latina. Buenos Aires: CLACSO.

Foucault, M. (1999a). “Clase del 5 de febrero de 1975”. En: Los anormales. Buenos Aires: F.C.E. (1999b). La verdad y las formas jurídicas. Barcelona: Gedisa.

Galvani, M. y Palma, J. (2005). "La hinchada de uniforme”. En: Hinchadas. Buenos Aires: Prometeo.

Gil, G. (2002). Fútbol e identidades locales. Dilemas de fundación y conflictos latentes en una ciudad "feliz". Buenos Aires: Miño y Dávila.

Gorelik, A. (1998). La grilla y el parque. Espacio público y cultura urbana en Buenos Aires, 1887-1936. Buenos Aires: Universidad Nacional de Quilmes.

Guterman, T. (2000) "El deporte profesional en el siglo XXI: inclusión, transformación y diversidad". Revista Lecturas: Educación Física y Deportes No 18. Obtenido el 19 de marzo de 2000 en http:// www.efdeportes.com/efd18/sigloxxi.htm. 
Hall, S. (1995). "New cultures for old". En: A place in the World? Places, culture and Globalizaton. Oxford University Press/ Open University (Trad. A. García Vargas).

Karasik, G. (1994). "Plaza Grande y Plaza Chica: Etnicidad y poder en la Quebrada de Humahuaca”. En: Cultura e identidad en el Noroeste argentino. Buenos Aires: CEAL.

_ (2000). "Tras la genealogía del diablo. Discusiones sobre la nación y el Estado en la frontera argentino-boliviana”. En: Fronteras, naciones e identidades. La periferia como centro. Buenos Aires: Ediciones CICCUS/ La Crujía.

- (2005). Etnicidad, cultura y clases sociales. Procesos de formación histórica de la conciencia colectiva en Jujuy, 1970-2003. Tesis Doctoral en Ciencias Sociales. Universidad Nacional de Tucumán.

Levatti, A. (1998). “Colón-Unión: violencia y rivalidad”. En: Deporte y Sociedad. Buenos Aires: Eudeba.

Ortíz, R. (2003). Lo próximo y lo distante. Japón y la modernidad-mundo. Buenos Aires: Interzona.

Ramírez Gallegos, J, P. (2003). “Fútbol e identidad regional en Ecuador”.En: Futbologías. Fútbol, Identidad y Violencia en América Latina. Buenos Aires: CLACSO.

Reguillo, R. (1995). “Escenarios de la identidad: el espacio urbano vs. el territorio”. En: En la calle otra vez. Las Bandas: identidad urbana y usos de la comunicación. México: Iteso.

_ (2002). "El otro antropológico. Poder y representación en una contemporaneidad sobresaltada". Análisi No 29.

_- (may. 2003). “Violencias y después. Culturas en reconfiguración”. En: Latin American Network Information Center. Obtenido el 24 de junio de 2007 en http://lanic.utexas.edu/project/etext/ llilas/cpa/spring03/culturaypaz/reguillo.pdf.

_ (2004). "Subjetividad, crisis y vida cotidiana. Acción y poder en la cultura". En: La cultura en las crisis latinoamericanas. Buenos Aires: CLACSO.

_- (2005a). Horizontes fragmentados. Comunicación, cultura, pospolítica. El (des)orden global y sus figuras. México: ITESO.

_- (2005b). “La razón re-encantada: magia, neoreligión y rituales en la era del colapso”. Comunicación y Medios No 16.

Segato, R, L. (1997). "Alteridades históricas/Identidades políticas: una crítica a las certezas del pluralismo global". Serie Antropología № 234.

_ (2004). "Territorio, soberanía y crímenes de segundo estado: la escritura en el cuerpo de las mujeres asesinadas en Ciudad Juárez". Serie Antropología № 362.

Sfez, L. (2005). Técnica e ideología. Un juego de poder. México: F.C.E.

Vila, P. (jul. 1993). "Las disputas de sentido común en la frontera norte. El «otro» en las narrativas de juarences y paceños”. Ponencia presentada en XIII Congreso Internacional de Ciencias Antropológicas y Etnológicas. México.

Villena Fiengo, S. (2000). "Imaginando la nación a través del fútbol: el discurso de la prensa costarricense sobre la hazaña mundialista de Italia '90”. En: Peligro de Gol. Buenos Aires: CLACSO.

\section{Artículos periodísticos:}

"Abre hoy su congreso el fútbol del interior. Habla Nucetelli. "Propiciamos la integración del país a través del fútbol" (1977, 15 de enero). Pregón.

"Clubes de siete provincias comprometen su asistencia al congreso de Jujuy" (1977, 13 de enero). Pregón. 
"El “Lobo". Los que lo querían ver caer, ven como asciende" (1994, 9 de junio). Pregón.

"Enfrentamiento Interior-AFA" (1977, 16 de enero). Pregón.

"Esta tarde en el "23 de agosto". Gimnasia buscará detener a los "santos", que vienen marchando" (2001, 11 de marzo). Pregón.

“Gimnasia lo hizo posible. El monstruo de mil cabezas parece haber despertado” (1994, 28 de abril). Pregón.

"Gimnasia un plato difícil de digerir. De un insulso gallina a un salado indigesto" (1994, 25 de abril). Pregón.

“Gimnasia y Esgrima. 'Nos trataron como si no fuéramos de este país’” (1994, 20 de junio). Pregón.

“Gimnasia y Esgrima. Comenzó a "meterse” en el clásico ante Juventud” (2000, 10 de octubre). Pregón.

"Jujuy debe hacerse sentir en Córdoba” (1994, 26 de abril). Pregón.

"La AFA dijo no al fútbol del interior" (1977, 19 de enero). Pregón.

"La fiesta que no fue" (2005, 26 de junio). Pregón.

“Norberto Testa. 'Hay que ganar el clásico por todo lo que significa'” (2001, 19 de octubre). Pregón.

"Por capricho de AFA. Gimnasia con River en Salta” (1975, 12 de diciembre). Pregón.

"Por un auténtico Nacional. Adhesiones a la iniciativa jujeña” (1977, 8 de enero). Pregón.

"Posición líder de Jujuy en el conflicto del fútbol nacional” (1977, 3 de febrero). Pregón.

"Proclama su verdad el fútbol del interior" (1977, 16 de enero). Pregón.

"Que sea una verdadera fiesta" (2002, 10 de noviembre). Pregón.

"Raúl Ulloa. 'No era un partido más” (2002, 11 de noviembre). El Tribuno de Salta.

"Raúl Ulloa. 'Nunca pedí disculpas al pueblo salteño” (2001, 15 de marzo). Pregón.

"Repudian la actitud de la P. Federal" (1994, 21 de junio). Pregón.

"s/t” (1992, 9 de mayo). Pregón.

"Se aguardan definiciones en el diferendo AFA-fútbol del interior. Sortean hoy los partidos del 'Metro' ” (1977, 18 de enero). Pregón. 


\section{Anexo 1: Mapa de la provincia de Jujuy}

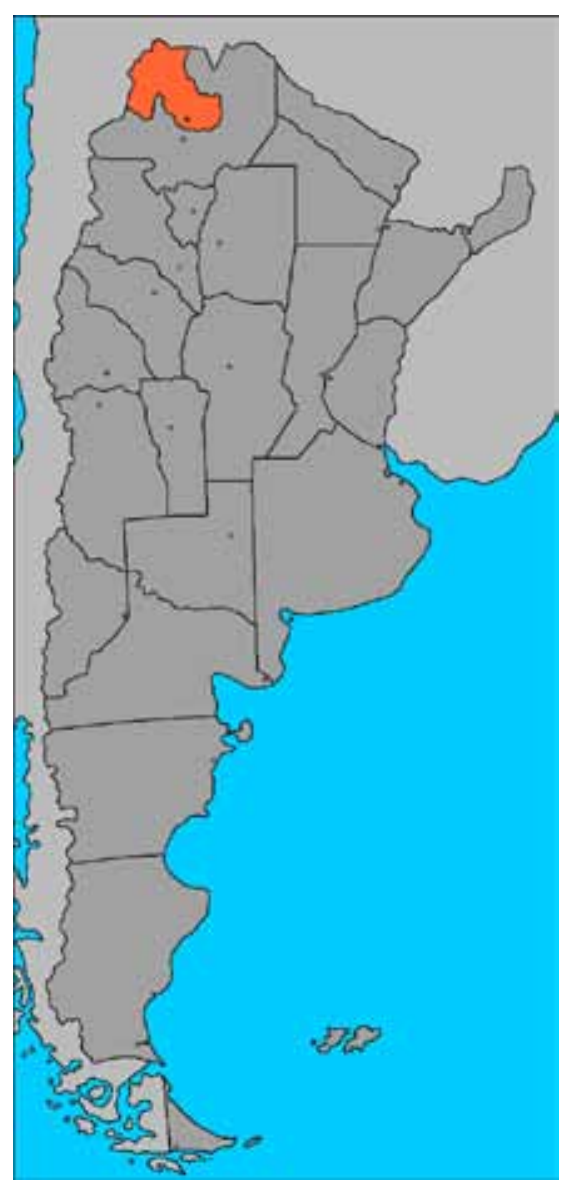

Fuente: http://www.losmejoresdestinos.com/destinos/jujuy/mapa_jujuy_argentina.gif 